Article

\title{
Regional Competition, Labor Force Mobility, and the Fiscal Behaviour of Local Governments in China
}

\author{
Gangqiang Yang ${ }^{1}$, Hong Chen ${ }^{1}$ and Xia Meng ${ }^{2, *}$ \\ 1 Institute for the Development of Central China, Wuhan University, Wuhan 430072, China; \\ gqyang@whu.edu.cn (G.Y.); chenhong_zby@whu.edu.cn (H.C.) \\ 2 China University of Geosciences (Wuhan), Wuhan 430074, China \\ * Correspondence: mengxia@cug.edu.cn
}

Received: 14 February 2019; Accepted: 21 March 2019; Published: 24 March 2019

check for updates

\begin{abstract}
At present, China is in a critical period of transition from labor-intensive industries to capital- and technology-intensive industries. Accordingly, the increasing labor force mobility among Chinese cities has promoted competition over production factors among regions, having a significant impact on local governments' fiscal expenditure structure. A theoretical analysis shows that the competition of livelihood public good expenditures is playing an increasingly important role in the factor flow competition. Different labor forces' demand for different public goods and local governments' demand for different labor forces affect the structural preference of local government fiscal expenditures. Based on panel data on Chinese prefecture-level cities in 2010-2016, this paper empirically tests the impact of different labor mobilities on the structure of local government fiscal expenditures, finding that current decision making on labor mobility is increasingly sensitive to the supply of livelihood public goods, and strengthening labor mobility has reversed the expenditure bias historically caused by the government's simple capital competition. After dividing the mobile labor force based on whether the labor is settled in the current year, the two labor force types' demand for different livelihood public goods was found to be different. To attract different labor inflows, local governments should promote an increase in relevant livelihood public good expenditures, showing a strategic fiscal expenditure structural bias. Specifically, with increasing new added general labor mobility, local goverments will increase the proportion of fiscal expenditures on education and medical care, combined with the increase of newly added registered labor mobility, which will correspondingly increase the proportion of environmental protection expenditures.
\end{abstract}

Keywords: labor mobility; regional competition; public goods; fiscal expenditure structure

\section{Introduction}

Chinese-style decentralization is characterized by a top-down political management system and extensive economic decentralization [1,2]. Such a decentralization system has greatly promoted the rapid development of local economies and caused significant growth in public good expenditures. However, the fiscal expenditures of many local governments are biased toward hard public goods such as infrastructure, while the supply of soft public goods such as education and medical care is insufficient.

Many studies attribute the bias of the government's expenditure structure to regional competition. In research on regional competition, the bias of local government expenditure structure, which is caused by the competition of the capital factor, has been widely recognized. Li and Shen [3] have studied the relationship between foreign direct investment (FDI) and government spending strategies. They believe that the competition among local governments in the flow of resources has led to strategic expenditures by local governments, which is evident in the competition of FDI; Zhang et al. [4] consider 
the competition mechanism among governments regarding "inviting investment" to be an important reason for the rapid growth in infrastructure investment in China. Additionally, direct competition among local governments for floating capital has a significant crowding-out effect on livelihood public good expenditures. As a result, local governments' competition for both FDI and domestic floating capital leads to the bias of their expenditure structure, which is clearly strategic $[5,6]$.

Another part of the literature focuses on the effect of yardstick competition on the local government expenditure structure (The "yardstick competition" here refers to the local governments competing on the supply of public goods, trying to provide more and better public goods than the competitors.) Zhou [7,8] and Li and Zhou [9] pointed out that the combination of top-down political centralization and fiscal decentralization has enabled regional officials to compete extensively in the economic field to achieve political advancement, which, in turn, has led to a lack of relative supply of livelihood public goods. This lack is evident in the early stage of economic development. With the development of the economy, the goal of regional competition has shifted from "GDP" alone to providing a higher level of livelihood public goods. The incentives for political promotion have gradually strengthened, and yardstick competition over livelihood public goods have begun to appear [10,11]. Zhou et al. [12] used the classical analysis framework of Besley and Case [13] to establish a theoretical model based on the actual situation in China and analysed the influence of yardstick competition on municipal-level education expenditures from the perspective of the promotion of officials. They found that there are positive effects of yardstick competition on improving the bias of the expenditure structure. Based on the results of Bordignon et al. [14] and Elhorst and Fréret [15], Wang [16] further applied the two-zone spatial econometric model to eliminate the influence of other mechanisms on adjacent areas, thus demonstrating the effects of yardstick competition on public good investment. This finding is basically consistent with the conclusions of Tsai [17]; that is, due to China's unique political cycle, the yardstick competition of local government expenditures is more complicated and more strategic.

Under the goal of maximizing their own interests, the decisions of local governments have "economic man" characteristics [18-20]. China is a highly politically centralized country. Officials at the mayor level are basically appointed by the central government, so officials compete fiercely in the region to achieve political advancement. In the case of limited local government revenue, they will weigh the distribution of fiscal expenditures and rationally arrange for productive expenditures and livelihood public goods expenditures. To gain comparative advantage in competition, regions will influence one another in their production factor allocation and fiscal expenditures. Therefore, capital competition among regions and yardstick competition in terms of investment attraction are all part of the competitive strategy of local governments, which has an impact on the expenditure structure of local governments.

In the early period of China's reform and opening up, the main form of local government competition was reflected in the competition for capital, which was determined by industrial development at that time. A large number of labor-intensive industries boomed, which corresponded to the fact that most of the labor force lacked professional knowledge and skills at that time. Capital- and technology-intensive industries are developing slowly. Correspondingly, capital supply is relatively scarce and the labor supply is sufficient. Therefore, the productivity of the capital factor was higher, while the labor force and other production factors generally had lower productivity. At the same time, due to the impact of household registration control and other reasons, labor mobility was not strong. Therefore, the basic assumption of the classical "Tiebout" model, the free flow of the population, cannot be satisfied, and the competition of livelihood public goods expenditure has not been empirically tested in China for a long time.

With the continuous advancement of the reform and opening up process, economic development in China has entered an innovative, high-quality development stage. The quality of labor and labor mobility is constantly improving, and the role of human capital in economic development is becoming more and more important. In 2016, the proportion of the labor force that had obtained professional 
technical qualifications reached 13.24\% (Data from the "China Workforce Dynamics Survey: 2017 Report".), and the total size of the floating population reached 245 million (Data from the "China Mobile Population Development Report 2017".). At the same time, livelihood public goods such as education and medical care are being increasingly taken into account in decision making on labor migration, making the reasons for labor migration more diversified [21-24]. Local governments have been unable to ignore the demand for livelihood public goods in the process of attracting labor inflows.

China is currently in a critical period of transition from labor-intensive industries to capital- and technology-intensive industries. In order to achieve economic transformation, local governments have appeared more sensitive to the needs of specific mobile labor than ever. Under such a circumstance, with the continuous reform speed of China's household registration system, the speed of labor mobility has gradually increased too. As a matter of fact, the importance of livelihood public goods expenditure competition in factor competition has become apparent.

As Keen and Marchand [25] show, because the liquidity of capital is much higher than labor mobility, local governments compete for limited capital and preferentially meet the needs of capital owners, leading to the productive bias of the expenditure structure. Therefore, how does the local government in China react to the sufficient labor force mobility that the current labor force shows? How will competition among local governments change? What kind of structural bias will these changes result in for local government fiscal expenditures?

As industry has developed and upgraded, knowledge and technology have become more and more indispensable. Undoubtedly, the labor force, as the carrier of these forces, is playing a more important role in economic development, which is leading local governments' to give equal attention to both capital and the labor force. Compared to the past, local governments need to research the labor force on a new level. Labor force mobility has changed their livelihood public goods demands, which is verified by the phenomenon of "Tiebout" philosophy of "voting with your feet" being widespread.

In this context of regional competition, the more frequently the labor force has moved, the more fierce local governments' competition has been. As a result, local governments have to promote labor investment in response.

The contribution of this paper is twofold: first, it constructs a theoretical model assuming that capital and labor are both mobile, and it derives the response function of the local government expenditure structure to heterogeneous labor mobility. Second, using data on Chinese prefecture-level cities for empirical testing, after solving the problems of endogeneity in the theoretical analysis, it confirms the existence of the mechanism by which labor mobility affects the structure of local government fiscal expenditures and analyses the differences caused by the heterogeneity of the labor force.

The rest of this article is organized as follows. Section 2 establishes a theoretical model of the impact of labor mobility on the structure of local government fiscal expenditures in the context of regional competition. Section 3 introduces empirical strategies and data sources. Section 4 analyses the empirical results, and Section 5 is the conclusion.

\section{Theoretical Model}

\subsection{Model Setting}

Compared with capital factor, the labor force factor has its own characteristics. On the one hand, it enters the production function as a factor of production to participate in factor competition; on the other hand, under the effects of the supply of public goods, it may flow as government expenditures change, leading to the breakdown of factor equilibrium. Therefore, this section attempts to separate this cyclic causality and to construct a response function of different fiscal expenditure items of local governments to different types of labor force mobility.

Now, assuming that there are two regions in the economic system $i$ and $-i\{1,2\}$, the total amount of private capital included in the entire system is $\bar{K}$, and the total amount of the two heterogeneous 
labor forces is $\bar{L}$ and $\bar{A}$, respectively (According to the needs of the research purposes, the division of heterogeneous labor here can be based on factors such as skill level, educational level, and family differences. In this article, we divide the labor force based on whether the mobile labor settled in cities in that year.), the capital and labor force owned by region $i$ is $K_{i}, L_{i}$, and $A_{i}$; thus, $\bar{K}=K_{i}+K_{-i}$, $\bar{L}=L_{i}+L_{-i}$, and $\bar{A}=A_{i}+A_{-i}$. The government provides productive expenditure $P_{i}$ and two non-productive expenditures (livelihood public good expenditures) $E_{i}^{1}$ and $E_{i}^{2}$ (This paper follows Barro's (1990) classical division of public expenditure, which is simply divided into productive expenditure and non-productive expenditure. The expenditure on livelihood public goods is equivalent to non-productive expenditure. Our considerations are as follows: Chinese officials compete fiercely for political promotion in the short term. In 2017, the average time of service of mayors in Chinese cities was 3.08 years, while livelihood public goods such as education and medical care may need a longer period of time to show economic benefits. Furthermore, if we allow livelihood public goods to have slight productivity, in addition to making the calculation more complex, there is no fundamental impact on the conclusions of this paper.). Without considering the congestion of fiscal expenditures [26], we consider only the crowding of consuming public goods. Applying the setting of Borcherding and Deacon [27], the following equations can be obtained:

$$
\begin{aligned}
& e_{i}^{1}=E_{i}^{1} * Z_{i}^{1} \\
& e_{i}^{2}=E_{i}^{2} * Z_{i}^{2}
\end{aligned}
$$

where $e_{i}^{1}$ and $e_{i}^{2}$ are the supply levels of two kinds of livelihood public goods that the residents of area $i$ actually enjoy. $Z_{i}^{1}$ and $Z_{i}^{2}$ can be expressed as the supply efficiency of regional public goods. The following theoretical section assumes that $Z_{i}^{1}$ and $Z_{i}^{2}$ are constants.

Based on Barro's [28] endogenous economic growth model of public expenditures, the Hicks-neutral Cobb-Douglas-type production function with the same scale return is used, $Y_{i}=$ $K_{i}^{\alpha} L_{i}^{\beta_{1}} A_{i}^{\beta_{2}} P_{i}^{\gamma}$, in which $\alpha+\beta_{1}+\beta_{2}+\gamma=1$, the parameters are positive, and the production function satisfies the Inada conditions.

Assuming that the multiple objectives of governments are economic growth and the provision of public goods to residents, the objective function is $U_{i}=\ln Y_{i}+c_{1} \ln e_{i}^{1}+c_{2} \ln e_{i}^{2}$, where $c_{1}$ and $c_{2}$ indicate the degree of the government's emphasis on the supply of two types of livelihood public goods, $e_{i}^{1}$ and $e_{i}^{2}$, relative to economic growth. Then, the optimal decision-making problem of local governments can be simplified to the following equations:

$$
\operatorname{Max} U_{i}=\ln Y_{i}+c_{1} \ln e_{i}^{1}+c_{2} \ln e_{i}^{2}=\alpha \ln K_{i}+\beta_{1} \ln L_{i}+\beta_{2} \ln A_{i}+\gamma \ln P_{i}+c_{1} \ln e_{i}^{1}+c_{2} \ln e_{i}^{2}
$$

For the sake of simplicity, the impact of local government budgets on expenditures and the special role of transfer payments are not considered. To set government revenue as $T_{i}$, the budget constraint of the government is as follows: (It is too easy for local governments to borrow money, which leads to a certain disconnection between tax revenue and expenditure when tax revenue grows slowly and the volume is small, and income is obtained through land sales and other simpler and faster ways to expand expenditure. In the view of local governments, the increase and decrease of fiscal revenue depend more on whether there are large-scale projects and changes in transfer payments from superiors, and the part that can increase through tax revenue is too small. Therefore, it may be acceptable to set $T_{i}$ as a total amount.)

$$
P_{i}+E_{i}^{1}+E_{i}^{2}=T_{i}
$$

In general, we assume that capital flows freely and that labor can flow partially. At this time, the free flow of capital needs to have the same rate of return in different regions to achieve equilibrium. 
Regardless of the impact of tax, in the case of no arbitrage, there is $\partial Y_{i} / \partial K_{i}=\partial Y_{-i} / \partial K_{-i}$. Thus, the condition for capital competition equilibrium is obtained as follows:

$$
\ln \frac{K_{i}}{K_{-i}}=\frac{1}{1-\alpha}\left(\beta_{1} \ln \frac{L_{i}}{L_{-i}}+\beta_{2} \ln \frac{A_{i}}{A_{-i}}+\gamma \ln \frac{P_{i}}{P_{-i}}\right)
$$

Since the labor force is only partially mobile, $L_{i}=\overline{l_{i}}+l_{i}$ and $A_{i}=\overline{a_{i}}+a_{i}$ exist, in which $\overline{l_{i}}$ and $\overline{a_{i}}$ are the number of two heterogeneous labor forces that are not mobile. The ratio of the number of flowing labor forces $l_{i}$ and $a_{i}$ to the total amount $L_{i}$ and $A_{i}$ is $d_{i}^{l}$ and $d_{i}^{a}$, where $d_{i}^{l}=l_{i} / L_{i}$ and $d_{i}^{a}=a_{i} / A_{i}$, representing the labor mobility of $L$ and $A$, respectively. At the same time, it is assumed that the total amount of the two types of labor flowing in the two regions is $\bar{l}$ and $\bar{a}$, satisfying $\bar{l}=l_{i}+l_{-i}$ and $\bar{a}=a_{i}+a_{-i}$. According to the setting of the above equation, we can obtain the following: $l_{i}=\frac{d_{i}^{l}}{1-d_{i}^{l}} \bar{l}_{i}$ and $a_{i}=\frac{d_{i}^{a}}{1-d_{i}^{a}} \overline{a_{i}}$.

At this point, consider the equilibrium of different labor flows, assuming that the utility functions of heterogeneous labor are $u_{i}^{l}=\ln w_{i}+\theta_{1} \ln e_{i}^{1}+\theta_{2} \ln e_{i}^{2}$ and $u_{i}^{a}=\ln m_{i}+\phi_{1} \ln e_{i}^{1}+\phi_{2} \ln e_{i}^{2}\left(u_{i}^{l}\right.$ and $u_{i}^{a}$ are the utility functions of the two kinds of labors $L$ and $A$, respectively.) and $\ln m_{i}$ indicate the utility of the two types of labor from economic income, and $\theta_{1} \ln e_{i}^{1}$ and $\theta_{2} \ln e_{i}^{2}$, and $\phi_{1} \ln e_{i}^{1}$ and $\phi_{2} \ln e_{i}^{2}$, are the direct effects of different labor forces from two public goods. The size difference between $1: \theta_{1}: \theta_{2}$ and $1: \phi_{1}: \phi_{2}$, respectively, reflect the degree of the influence of the demand for livelihood public goods on the choice of residence and the differences in the preferences of labor forces for different types of livelihood public goods caused by the heterogeneity of labor. $w_{i}=\frac{\partial Y_{i}}{\partial L_{i}}$ and $m_{i}=\frac{\partial Y_{i}}{\partial A_{i}}$, and $w_{i}$ and $m_{i}$, are the direct economic rewards for the two types of labor, which can simply be regarded as wages.

When there is an equilibrium of labor competition, the same labor has equal benefits in different regions, $u_{i}^{l}=u_{-i}^{l}$ and $u_{i}^{a}=u_{-i}^{a}$; thus, Equations (6)-(7) can be obtained as follows:

$$
\begin{aligned}
& \alpha \ln \frac{K_{i}}{K_{-i}}+\left(\beta_{1}-1\right) \ln \frac{L_{i}}{L_{-i}}+\beta_{2} \ln \frac{A_{i}}{A_{-i}}+\gamma \ln \frac{P_{i}}{P_{-i}}+\theta_{1} \ln \frac{e_{i}^{1}}{e_{-i}^{1}}+\theta_{2} \ln \frac{e_{i}^{2}}{e_{-i}^{2}}=0 \\
& \alpha \ln \frac{K_{i}}{K_{-i}}+\beta_{1} \ln \frac{L_{i}}{L_{-i}}+\left(\beta_{2}-1\right) \ln \frac{A_{i}}{A_{-i}}+\gamma \ln \frac{P_{i}}{P_{-i}}+\phi_{1} \ln \frac{e_{i}^{1}}{e_{-i}^{1}}+\phi_{2} \ln \frac{e_{i}^{2}}{e_{-i}^{2}}=0
\end{aligned}
$$

According to capital and the two kinds of labor force competition equilibrium conditions in equations (5)-(7), the competition equation of production factors (8)-(10) can be obtained by calculating the following:

$$
\begin{gathered}
\ln \frac{K_{i}}{K_{-i}}=\ln \frac{P_{i}}{P_{-i}}+\frac{\beta_{1} \theta_{1}+\beta_{2} \phi_{1}}{\gamma} \ln \frac{e_{i}^{1}}{e_{-i}^{1}}+\frac{\beta_{1} \theta_{2}+\beta_{2} \phi_{2}}{\gamma} \ln \frac{e_{i}^{2}}{e_{-i}^{2}} \\
\ln \frac{\overline{l_{i}}+l_{i}}{\overline{l_{-i}}+l_{-i}}=\ln \frac{L_{i}}{L_{-i}}=\ln \frac{P_{i}}{P_{-i}}+\frac{\left(1-\alpha-\beta_{2}\right) \theta_{1}+\beta_{2} \phi_{1}}{\gamma} \ln \frac{e_{i}^{1}}{e_{-i}^{1}}+\frac{\left(1-\alpha-\beta_{2}\right) \theta_{2}+\beta_{2} \phi_{2}}{\gamma} \ln \frac{e_{i}^{2}}{e_{-i}^{2}} \\
\ln \frac{\overline{a_{i}}+a_{i}}{\overline{a_{-i}}+a_{-i}}=\ln \frac{A_{i}}{A_{-i}}=\ln \frac{P_{i}}{P_{-i}}+\frac{\left(1-\alpha-\beta_{1}\right) \phi_{1}+\beta_{1} \theta_{1}}{\gamma} \ln \frac{e_{i}^{1}}{e_{-i}^{1}}+\frac{\left(1-\alpha-\beta_{1}\right) \phi_{2}+\beta_{1} \theta_{2}}{\gamma} \ln \frac{e_{i}^{2}}{e_{-i}^{2}}
\end{gathered}
$$

Suppose that local governments compete based on simultaneously considering the flow of capital and labor to achieve economic growth and to provide livelihood public goods: Max $U_{i}$. Subject to the government budget constraint (4) and factor competition equations (8)-(10), construct a Lagrangian function to find the extremum and obtain the equation: 


$$
\begin{aligned}
& \frac{1}{P_{i}}\left(\frac{\alpha}{\frac{K_{i}}{K_{-i}}+1}+\frac{\beta_{1}}{\frac{L_{i}}{L_{-i}}+1}+\frac{\beta_{2}}{\frac{A_{i}}{A_{-i}}+1}+\gamma\right) \\
& =\frac{1}{E_{i}^{1}}\left(\frac{\alpha}{K_{i}+1} \frac{\beta_{1} \theta_{1}+\beta_{2} \phi_{1}}{\gamma}+\frac{\beta_{1}}{K_{i}} \frac{\left(\beta_{1}+\gamma\right) \theta_{1}+\beta_{2} \phi_{1}}{\gamma}+\frac{\beta_{2}}{\frac{L_{i}}{L_{-i}}+1} \frac{\left(\beta_{2}+\gamma\right) \phi_{1}+\beta_{1} \theta_{1}}{\gamma}+c_{1}\right)
\end{aligned}
$$

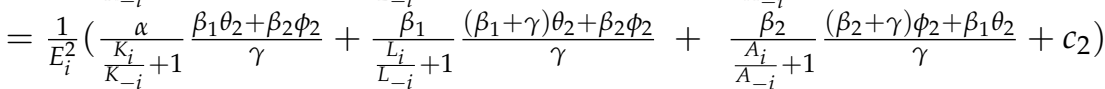

Substituted as

$$
\begin{gathered}
\gamma^{\prime \prime}=\frac{\alpha}{\frac{K_{i}}{K_{-i}}+1}+\frac{\beta_{1}}{\frac{L_{i}}{L_{-i}}+1}+\frac{\beta_{2}}{\frac{A_{i}}{A_{-i}}+1}+\gamma \\
c_{1}^{\prime \prime}=\frac{\alpha}{\frac{K_{i}}{K_{-i}}+1} \frac{\beta_{1} \theta_{1}+\beta_{2} \phi_{1}}{\gamma}+\frac{\beta_{1}}{\frac{L_{i}}{L_{-i}}+1} \frac{\left(\beta_{1}+\gamma\right) \theta_{1}+\beta_{2} \phi_{1}}{\gamma}+\frac{\beta_{2}}{\frac{A_{i}}{A_{-i}}+1} \frac{\left(\beta_{2}+\gamma\right) \phi_{1}+\beta_{1} \theta_{1}}{\gamma}+c_{1} \\
c_{2}^{\prime \prime}=\frac{\alpha}{K_{i}+1} \frac{\beta_{1} \theta_{2}+\beta_{2} \phi_{2}}{\gamma}+\frac{\beta_{1}}{\frac{L_{i}}{L_{-i}}+1} \frac{\left(\beta_{1}+\gamma\right) \theta_{2}+\beta_{2} \phi_{2}}{\gamma}+\frac{\beta_{2}}{\frac{A_{i}}{A_{-i}}+1} \frac{\left(\beta_{2}+\gamma\right) \phi_{2}+\beta_{1} \theta_{2}}{\gamma}+c_{2} \text {, simplify the formula, and }
\end{gathered}
$$

the proportion of each expenditure can be obtained as follows:

$$
\begin{aligned}
& \frac{P_{i}}{T_{i}}=\frac{\gamma^{\prime \prime}}{\gamma^{\prime \prime}+c_{1}^{\prime \prime}+c_{2}^{\prime \prime}} \\
& \frac{E_{i}^{1}}{T_{i}}=\frac{c_{1}^{\prime \prime}}{\gamma^{\prime \prime}+c_{1}^{\prime \prime}+c_{2}^{\prime \prime}} \\
& \frac{E_{i}^{2}}{T_{i}}=\frac{c_{2}^{\prime \prime}}{\gamma^{\prime \prime}+c_{1}^{\prime \prime}+c_{2}^{\prime \prime}}
\end{aligned}
$$

\subsection{Model Analysis}

Under the background of regional competition, the supply of livelihood public goods has a sufficient impact on decision making on labor mobility. The greater the labor mobility is, the more labor forces need to compete among regions. To attract labor inflow, local governments increase expenditures to meet the demand of migrant labor for livelihood public goods, leading to the bias of the fiscal expenditure structure toward livelihood public good expenditures. This bias is the specific influence mechanism of labor mobility on the fiscal expenditure structure of local governments. Accordingly, we put forth the following propositions:

Proposition 1. When the responsiveness of local governments to the demand of mobile labor force reaches a certain level, the greater the labor mobility is, the higher the proportion of livelihood expenditures in local government fiscal expenditures, improving the structure of fiscal expenditures.

Proof. Proof. Equations (8)-(14) show that changes in local government expenditures will cause the flow of various factors in regional competition. The change in resource allocation caused by the factor flow, in turn, will lead to changes in the expenditure structure of the government in maximizing its objective function. In particular, since the labor force can flow to a certain extent, local governments begin to consider the preferences of different labor demands and attract the inflow of labor by providing desirable public goods.

Analysing the impact of labor mobility on the structure of expenditure (Due to space limitations, only the influence of the mobility of factor $L$ on the expenditure structure is listed here. Because of the symmetry of the model settings, the mobility effect of production factor $A$ is consistent with the $L$ form, except that the parameter settings are different.), 


$$
\frac{\partial\left(E_{i}^{1} / T_{i}\right)}{\partial d_{i}^{l}}=\frac{\partial\left(E_{i}^{1} / T_{i}\right)}{\partial\left(\frac{\beta_{1}}{1+L_{i} / L_{-i}}\right)} \frac{\partial\left(\frac{\beta_{1}}{1+L_{i} / L_{-i}}\right)}{\partial\left(L_{i} / L_{-i}\right)} \frac{\partial\left(L_{i} / L_{-i}\right)}{\partial d_{i}^{l}}
$$

Through calculation, we can obtain the following: $\frac{\partial\left(\frac{\beta_{1}}{1\left(L_{i} / L_{-i}\right.}\right)}{\partial\left(L_{i} / L_{-i}\right)}<0 ; \frac{\partial\left(L_{i} / L_{-i}\right)}{\partial d_{i}^{l}}>0$.

$$
\begin{aligned}
& \frac{\partial\left(E_{i}^{1} / T_{i}\right)}{\partial\left(\frac{\beta_{1}}{1+\Lambda_{1} / L_{-i}}\right)}=\left\{\left[\theta_{1}+\frac{\beta_{2}}{\gamma}\left(\theta_{1} \phi_{2}-\theta_{2} \phi_{1}\right)\right] \frac{\alpha}{\frac{K_{i}}{K_{-i}}+1}+\left[\frac{\left(\theta_{1} \phi_{2}-\theta_{2} \phi_{1}\right)(1-\alpha)}{\gamma}+\theta_{1}\right.\right. \\
& \left.-\phi_{1}\right] \frac{\beta_{2}}{\frac{\beta_{i}}{A_{-i}}+1}+\beta_{2}\left(\phi_{1}+\frac{c_{2} \phi_{1}}{\gamma}-\frac{c_{1} \phi_{2}}{\gamma}\right)+\left(\beta_{1}+\gamma\right)\left(\theta_{1}+\frac{c_{2} \theta_{1}}{\gamma}\right. \\
& \left.\left.-\frac{c_{1} \theta_{2}}{\gamma}\right)-c_{1}\right\} /\left(\gamma^{\prime \prime}+c_{1}^{\prime \prime}+c_{2}^{\prime \prime}\right)^{2}
\end{aligned}
$$

Regardless of the heterogeneity of the labor force, we have $\theta_{1}=\phi_{1}$ and $\theta_{2}=\phi_{2}$. When $c_{1}=c_{2}=0$, local governments do not care about the supply of livelihood public goods. Thus, we can obtain $\frac{\partial\left(E_{i}^{1} / T_{i}\right)}{\partial\left(\frac{\beta_{1}}{1+L_{i} / L_{-i}}\right)}>0$ and $\frac{\partial\left(E_{i}^{1} / T_{i}\right)}{\partial d_{i}^{l}}<0$. When $c_{1}=\theta_{1}$ and $c_{2}=\theta_{2}$, the government's expenditure preference for livelihood public goods is consistent with that of the mobile labor force, which indicates that local governments are sufficiently responding to the demand of the mobile labor force. We can obtain $\frac{\partial\left(E_{i}^{1} / T_{i}\right)}{\partial\left(\frac{\beta 1}{1+L_{i} / L_{-i}}\right)}<0$ and $\frac{\partial\left(E_{i}^{1} / T_{i}\right)}{\partial d_{i}^{l}}=\frac{\partial\left(E_{i}^{1} / T_{i}\right)}{\partial d_{i}^{a}}>0$.

Because $\partial\left(\frac{\partial\left(E_{i}^{1} / T_{i}\right)}{\partial\left(\frac{\beta_{1}}{1+L_{i} / L_{-i}}\right)}\right) / \partial c_{1}<0$, in the range of $\left(0, \theta_{1}\right)$, the point $c_{1}=\bar{c}_{1}$ satisfies that $\frac{\partial\left(E_{i}^{1} / T_{i}\right)}{\partial\left(\frac{\beta_{1}}{1+L_{i} / L_{-i}}\right)}=$ 0 and $\frac{\partial\left(E_{i}^{1} / T_{i}\right)}{\partial d_{i}^{l}}=0$. When $c_{1}>\bar{c}_{1}$, we can obtain $\frac{\partial\left(E_{i}^{1} / T_{i}\right)}{\partial d_{i}^{l}}>0$. That is, when the responsiveness of local governments to the demand of mobile labor force reaches a certain level, the greater the labor mobility is, and the higher the proportion of expenditure on livelihood public goods. Yin and Xu [29] discussed the bias of local governments' fiscal expenditure structure caused by local governments' lack of adequate response to the needs of residents in their jurisdictions. Under these circumstances, response will be improved.

Proposition 2. Because local governments tend to attract different types of labor inflows, who have different needs for livelihood public goods, different labor mobilities have different effects on different livelihood public goods expenditures.

Proof. Within livelihood public goods expenditures, $\frac{\left(1-\alpha-\beta_{2}\right) \theta_{1}+\beta_{2} \phi_{1}}{\gamma}-\frac{\left(1-\alpha-\beta_{1}\right) \phi_{1}+\beta_{1} \theta_{1}}{\gamma}=\theta_{1}-\phi_{1}$ and $\frac{\left(1-\alpha-\beta_{2}\right) \theta_{2}+\beta_{2} \phi_{2}}{\gamma}-\frac{\left(1-\alpha-\beta_{1}\right) \phi_{2}+\beta_{1} \theta_{2}}{\gamma}=\theta_{2}-\phi_{2}$. The preference of heterogeneous labor for different public goods leads to different degrees of sensitivity to different livelihood public good expenditures. The difference in specific expenditure attractiveness depends on the differences between $\theta_{1}$ and $\theta_{2}$ and $\phi_{1}$ and $\phi_{2}$. The proof of proposition 1 shows that this difference will lead to a difference in the influence of heterogeneous labor mobility on the structure of government fiscal expenditures. In particular, when $\theta_{1}>\phi_{1}$ and $\theta_{2}>\phi_{2}$, the competition of all livelihood public good expenditures has a greater impact on labor $L$ than on labor $A$, and thus, the mobility of labor $L$ has a greater impact on the structure of government fiscal expenditures.

\section{The Empirical Strategy}

\subsection{Benchmark Model Setting}

Based on the current situation of China's population mobility and local government fiscal expenditures, this paper divides the types of mobile labor; empirically tests the impact of heterogeneous labor mobility on local government education, medical care and environmental protection expenditures; 
and verifies the responsiveness of local governments. In China, the population is divided according to the household registration system; public goods have been provided on this basis for a long time. Local governments may have different levels of responsiveness to the different livelihood public good demands of the newly added registered labor force and the nonregistered labor force (The so-called newly added registered labor force is the labor force that settled in that year.), which, in turn, leads to different expenditure biases. Therefore, the newly added urban migrant labor force of the year is divided into the registered labor force and the nonregistered labor force of the current year (this article refers to nonregistered labor as general labor). The following empirical model is constructed:

$$
y_{i t}=\eta_{0}+\eta_{1} l d h j_{i t}+\eta_{2} l d l o w_{i t}+\bar{\eta} X_{i t}+\mu_{i}+\sigma_{t}+\epsilon_{i t}
$$

where $i$ represents the city, $t$ represents time, and the dependent variable $y_{i t}$ represents the proportion of a certain livelihood public good expenditures, which is expressed as the proportion of education expenditures (edubili), the proportion of medical care expenditures (medbili), and the proportion of environmental protection expenditures (envbili). $\mu_{i}$ and $\sigma_{t}$ are urban fixed effects and time fixed effects, respectively.

$l d h j$ and ldlow are the main explanatory variables for the mobility of the registered labor force and the general labor force, respectively. Due to the lack of macro data on the migration rate of migrants, and drawing on the ideas of $\mathrm{Xu}$ and $\mathrm{Li}$ [30] and $\mathrm{Wu}$ and Liu [26], the following indicators were constructed (Limited by data, this paper assumes that the ratio of labor to population is a constant. Therefore, the labor mobility can be measured by the population mobility.).

Newly added registered labor mobility rate $(l d h j)=($ registered population at the end of the year - registered population at the end of the last year)/registered population at the end of the last year the natural population growth rate.

Newly added general labor mobility rate $($ ldlow) $=$ (newly added permanent resident population in the current year - permanent resident population at the end of last year $\times$ the natural population growth rate - newly added registered population)/permanent resident population at the end of last year.

$X_{i t}$ is a set of variables that control the economic, sociodemographic, and fiscal characteristics of a city. Drawing on existing research [31,32], the economic characteristics include per capita GDP, per capita savings deposit balance, per capita wage, per capita FDI, the ratio of secondary industry output value to GDP, the ratio of tertiary industry output value to GDP, total employees accounted for by the population ratio, the proportion of employees in the institution at the end of the year, and the unemployment rate. The sociodemographic variables include population density, the number of telephones per capita, the number of books in a library for every 100 people, the proportion of primary school students, and the proportion of secondary school students. The fiscal variables include government size and the financial self-sufficiency rate. Taking 2007 as the base period, we use the annual GDP deflation index of each province to reduce the economic variables (except proportional data) to eliminate the impact of price changes. At the same time, the other variables, except for the proportional data, are logarithmized.

\subsection{The Treatment of Problems of Endogeneity and the Analysis of the Influencing Mechanism}

According to equations (1)-(2) for the supply level of livelihood public goods and the labor competition equations (9)-(10), labor mobility ldhj and ldlow are affected by the supply of livelihood public goods. When the expenditures of livelihoods are equal among local governments, the higher the level of supply of public goods is, and the more likely the government is to win in the competition of labor factors, thus attracting more labor settlers and general labor inflows. Therefore, it is reasonable to suspect that there may be a lack of variables in the benchmark model (16) to control for the supply level of livelihood public goods, with problems of endogeneity thus arising. Eliminating the impact 
of the supply level of livelihood public goods on labor mobility solves these problems; this paper considers the following two methods.

The first method is to use instrumental variable (IV) estimation. To ensure the robustness of the conclusion, this paper selects two sets of indicators as instrumental variables. First, the average values of $l d h j$ and ldlow of all cities in the province, pldhj and pldlow, and the average labor mobility of the other cities in the same province except this city, ppldhj and ppldlow, are selected as instrumental variables. The missing variable, the supply level of livelihood public goods, involves a problem of endogeneity by simultaneously affecting the labor mobility of $l d h j$ and $l d l o w$ and the proportion of expenditures $y$. Using the provincial average pldhj and pldlow to measure the overall population mobility attractiveness of the province and labor mobility ppldhj and ppldlow in other cities in the same province that are not directly affected by the supply of local public goods can avoid such problems of endogeneity. Second, ldhj and ldlow lag phase 1 are added to the set of instrumental variables. The instrumental variables will be tested with regard to whether they are weak instrumental variables and with regard to overidentification to subsequently verify the rationality of the instrumental variables.

The second method is to construct indicators to control the supply level of livelihood public goods. At the same time, construct the interaction items of the supply level of livelihood public goods and labor mobility ldhj and ldlow (To avoid multicollinearity and facilitate comparative analysis, all the interaction items in this paper are centralized.) to analyse whether a certain supply level of livelihood public goods can affect the inflow of labor and thus lead to expenditure structural bias. The following empirical model is constructed as follows:

$$
y_{i t}=\eta_{0}+\eta_{1} l d h j_{i t}+\eta_{2} l d l o w_{i t}+\eta_{3} s y_{i t}+\eta_{4} s y_{i t} \times l d h j_{i t}+\eta_{5} s y_{i t} \times l d l o w w_{i t}+\bar{\eta} X_{i t}+\mu_{i}+\sigma_{t}+\epsilon_{i t}
$$

where sy represents the supply level of livelihood public good expenditures. Specifically, for education expenditures, the primary school teacher-student ratio and the middle school teacher-student ratio are used to construct the comprehensive index edusy; for medical care expenditures, the per capita number of doctors and the per capita number of beds are used to construct the comprehensive index medsy; for environmental protection expenditures, the urban domestic sewage treatment rate and the harmless treatment rate of domestic garbage are selected to construct the comprehensive index envsy (Specifically, the weights of the two subindicators for the three livelihood public good expenditures are respectively assigned as $(50 \%, 50 \%),(75 \%, 25 \%)$, and $(25 \%, 75 \%)$. Since the conclusions obtained by assigning different weights remain basically unchanged, only the results of assigning the first weights are reported in Table 4.).

\subsection{Inspection of the Regional Competition Mechanismn}

To verify the existence of a regional competition mechanism in practice and to examine the impact of labor mobility on the local government fiscal expenditure structure under different levels of regional competition, the following empirical model is constructed:

$$
y_{i t}=\eta_{0}+\eta_{1} l d h j_{i t}+\eta_{2} l d l o w_{i t}+\eta_{6} x z_{i t}+\eta_{7} x z_{i t} \times l d h j_{i t}+\eta_{8} x z_{i t} \times l d l o w_{i t}+\bar{\eta} X_{i t}+\mu_{i}+\sigma_{t}+\epsilon_{i t}
$$

where $x z_{i t}$ is a variable representing the degree of competition among local governments, including $x z 1 x$ and $x z 1$. Referring to Hatfield and Kosec [33], we use the number of counties included in the city $x z 1 x$ as the main indicator to measure the degree of local government competition. The more counties there are, the stronger the competition within prefecture-level cities will be, which may show a change in the fiscal expenditure structure at the overall level of prefecture-level cities. To ensure the robustness of the conclusion, we also select the total number of counties and county-level cities included in each prefecture-level city $x z 1$ as another set of indicators. To control the endogenous effect of the main explanatory variables, pldhj, pldlow, ppldhj, and ppldlow are also used as instrumental variables of $l d h j$ and ldlow. At the same time, the interaction items of these indicators and the variables regarding 
the level of local government competition are constructed and used as instrumental variables of the interaction items in the model.

\subsection{Data Sources and Descriptive Statistics}

To verify the existence of the influencing mechanism of the theoretical analysis, this paper conducts empirical analysis based on the relevant data on China's 274 prefecture-level cities in 2010-2016, among them the household registration population, education expenditures, and the data on the main control variables are from the "China Urban Statistical Yearbook" for these years. The data on permanent residents, medical care expenditures, and environmental protection expenditures come from the statistical yearbooks and statistical bulletins of the provinces and prefecture-level cities. Some of the early missing data are from the 2011-2014 "China Regional Economic Statistics Yearbook" (Because of the construction of the labor mobility indicators and the use of a lag period as instrumental variables, the household registration and resident population data collected in this paper are from as early as 2008.). The data on administrative divisions come from China's administrative division network. Since the administrative divisions disclosed on the website were approved by the State Council in the current year rather than directly changing, the data in this area were lagged one year.

Considering the particularity of the municipality in China, this paper deletes the samples of four municipalities to avoid the occurrence of outliers (The municipalities here refer to cities directly under the jurisdiction of the central government. In China, they include Beijing, Shanghai, Tianjin, and Chongqing. We have also used the data set of the four municipalities not deleted for regression analysis, and the conclusion remains basically unchanged. However, because the area and administrative level of four municipalities are much higher than those of ordinary prefecture-level cities, in order to eliminate the impact of extreme values, we deleted them.). To eliminate the impact of administrative changes on government expenditures, this paper deletes the sample of prefecture-level cities with changes in administrative divisions from 2010 to 2016. Due to the absence and confusion of permanent population data and household registration data in northeast China, the empirical regression does not include cities in northeast China (The northeastern region of China refers to the three provinces of Heilongjiang, Jilin, and Liaoning.). At the same time, due to the confusion between the household registration population and the resident population data of different yearbooks, the statistical yearbook data of each city is adjusted (The specific adjustment methods are as follows: first, cities with a difference between the resident population data and the household registration population data of less than 0.5 million are selected. If the two types of population data are very close for many years and statistical errors cannot be excluded according to the municipal statistical yearbook data, this part of the observations. Second, for the city sample data showing a household registration population change of more than $5 \%$ in one year, verify the reason for the large change. If it is not possible to rule out possible changes in statistical policies, delete this part of the observations. Finally, for the very few intermediate missing values in the remaining samples, use interpolation to fill in the data. Due to the complexity of this data processing method, we have also tried to regress the data set that has not been processed in this way, and the conclusion is basically unchanged.). Finally, for the very few intermediate missing values in the remaining samples, interpolation is used to fill in the data. The final collected data set contains certain missing values. The specific situation can be seen in Table 1 . 
Table 1. Variable definitions and summary statistics.

\begin{tabular}{|c|c|c|c|c|c|c|}
\hline Variables & Definition & $\mathbf{N}$ & Mean & Min & Max & SD \\
\hline edubili & the proportion of education expenditures & 1853 & 0.1838 & 0.0357 & 0.3562 & 0.0409 \\
\hline medbili & the proportion of medical care expenditures & 1786 & 0.0877 & 0.0184 & 0.2092 & 0.0247 \\
\hline envbili & $\begin{array}{c}\text { the proportion of environmental protection } \\
\text { expenditures }\end{array}$ & 1418 & 0.0298 & 0.0017 & 0.1430 & 0.0151 \\
\hline$l d h j$ & the mobility of the registered labor force & 2330 & -0.0008 & -0.0505 & 0.0429 & 0.0080 \\
\hline ldlow & the mobility of the general labor force & 2033 & -0.0012 & -0.1357 & 0.3873 & 0.0221 \\
\hline pldhj & the average $l d h j$ of all cities in the province & 2386 & -0.0008 & -0.0268 & 0.0169 & 0.0046 \\
\hline pldlow & the average ldlow of all cities in the province & 2081 & -0.0011 & -0.0754 & 0.1206 & 0.0118 \\
\hline ppldhj & $\begin{array}{c}\text { the average } l d h j \text { of the other cities in the same } \\
\text { province }\end{array}$ & 2022 & -0.0005 & -0.1652 & 0.0771 & 0.0083 \\
\hline ppldlow & $\begin{array}{l}\text { the average ldlow of the other cities in the same } \\
\text { province }\end{array}$ & 2022 & -0.0011 & -0.0813 & 0.1657 & 0.0125 \\
\hline edusy1 & the supply level of education & 2656 & 0.0678 & 0.0360 & 0.1520 & 0.0138 \\
\hline hossy1 & the supply level of medical care & 2316 & 28.3972 & 8.2814 & 87.2159 & 9.1344 \\
\hline envsy1 & the supply level of environmental protection & 2429 & 0.8157 & 0.0099 & 2.1279 & 0.1682 \\
\hline$x z 1$ & $\begin{array}{l}\text { the number of counties and county-level cities } \\
\text { included in the prefecture-level city }\end{array}$ & 2656 & 5.1995 & 0 & 22 & 3.5064 \\
\hline$x z 1 x$ & $\begin{array}{l}\text { the number of counties included in the } \\
\text { prefecture-level city }\end{array}$ & 2656 & 4.0881 & 0 & 18 & 3.2818 \\
\hline $\ln p g d p$ & logarithm of per capita GDP & 2429 & 10.2096 & 8.1267 & 12.2479 & 0.6348 \\
\hline Indensity & population density & 2656 & 5.7138 & 1.5728 & 7.8816 & 0.8941 \\
\hline $\operatorname{lnsm}$ & per capita savings deposit balance & 2654 & 9.7750 & 7.0894 & 12.4209 & 0.7266 \\
\hline lnwage & per capita wage & 2656 & 10.3483 & 8.3959 & 12.4591 & 0.3507 \\
\hline lnbook & the number of books in a library for every 100 people & 2655 & 3.5054 & 0.4187 & 7.4597 & 0.8401 \\
\hline Inperphone & the number of telephones per capita & 2655 & -0.3613 & -3.0964 & 2.2819 & 0.5881 \\
\hline pubtoall & the proportion of en & 2621 & 0.5346 & 0.0551 & 0.9492 & 0.1290 \\
\hline all_towork & total employees accounted for by the population ratio & 2621 & 0.2250 & 0.0429 & 2.5086 & 0.1933 \\
\hline zfbig & goyernment cize & 2656 & 0.1749 & 0.0437 & 1.0268 & 0.0975 \\
\hline nonworkrate & the unemployment rate & 2616 & 0.0306 & 0.0021 & 0.2179 & 0.0177 \\
\hline finfree & the financial self-sufficiency rate & 2656 & 0.4758 & 0.0544 & 1.5413 & 0.2296 \\
\hline$g d p 3$ & the ratio of tertiary industry output value to GDP & 2655 & 0.3703 & 0.0976 & 0.7635 & 0.0866 \\
\hline$g d p 2$ & the ratio of secondary industry output value to GDP & 2655 & 0.4927 & 0.1495 & 0.8975 & 0.1036 \\
\hline lnpfdi & per capita FDI & 2532 & 5.7189 & -0.6625 & 9.6275 & 1.5969 \\
\hline midbili & the proportion of secondary school s & 2656 & 0.0545 & 0.0182 & 0.1493 & 0.0148 \\
\hline pribili & the proportion of primary school students & 2656 & 0.0721 & 0.0245 & 0.3689 & 0.0268 \\
\hline
\end{tabular}

Note: $\mathrm{N}=$ Number of observations, SD = Standard deviation.

According to Table 1, the variables vary in Chinese cities. Among the local government fiscal expenditures data, local governments whose education and health spending account for the largest proportion of total fiscal spend about 10 times more than those whose education and health spending account for the smallest of total fiscal expenditure. What is more, the gap is even more than 80 times between the two extreme values of local governments on environmental protection expenditure. There is the same corresponding large difference of labor mobility data between different local governments. Considering the vast size of China and the wide gap in the level of economic development in various regions, in order to make a more meaningful comparison, we divided China into three regions, the eastern, the central, and the western, and compared the data of Chinese cities. As Table 2 indicaties, the proportion of education spending in eastern Chinese cities is significantly higher than in other regions in terms of the lowest, highest, and average. Cities in different regions do not show much difference in terms of health care and environmental spending. In terms of labor mobility, the eastern region is the only area with an average value greater than 0 . This represents the current situation in China. The eastern region has a higher level of economic development and supply of public goods, and attracts a large number of immigrants from the central and western regions. 
Table 2. Differences in government expenditure and labor mobility among cities in China.

\begin{tabular}{ccccc}
\hline Variables & Location & Mean & Min & Max \\
\hline \multirow{3}{*}{ edubili } & eastern region & 0.2042 & 0.1099 & 0.3562 \\
& central region & 0.1841 & 0.0844 & 0.2710 \\
& western region & 0.1725 & 0.0436 & 0.2724 \\
\hline \multirow{3}{*}{ medbili } & eastern region & 0.0863 & 0.0326 & 0.2046 \\
& central region & 0.0963 & 0.0392 & 0.1653 \\
& western region & 0.0886 & 0.0312 & 0.1474 \\
\hline \multirow{3}{*}{ envbili } & eastern region & 0.0291 & 0.0017 & 0.1430 \\
& central region & 0.0274 & 0.0057 & 0.0937 \\
& western region & 0.0328 & 0.0038 & 0.1190 \\
\hline \multirow{3}{*}{ ldhj } & eastern region & 0.0006 & -0.0316 & 0.0329 \\
& central region & -0.0029 & -0.0393 & 0.0349 \\
& western region & -0.0020 & -0.0398 & 0.0429 \\
\hline \multirow{2}{*}{ ldlow } & eastern region & 0.00004 & -0.1000 & 0.3873 \\
& central region & -0.0002 & -0.1257 & 0.1999 \\
& western region & -0.0005 & -0.1357 & 0.1805 \\
\hline
\end{tabular}

\section{Results}

\subsection{Baseline Regression Results}

According to the estimation strategy mentioned above, the regression model is used to verify the impact of different types of labor mobility on the proportion of different livelihood public good expenditures, to provide evidence for propositions 1 and 2. The estimated results of model (16) are shown in Table 3. The estimates using both sets of instrumental variables passed the weak instrumental variables test and the overidentification test [34,35] (The rk Wald F value is greater than 10 and is checked by a $5 \%$ threshold. The Hansen $\mathrm{J}$ test does not reject the null hypothesis. The first set of instrumental variables' estimation regression results is listed for comparison with the fixed effect model (see Table 3). The second set of instrumental variables' estimation regression results is shown in Table A1. The estimation results of the two groups of variables are essentially the same.). The estimation results of the ordinary two-way fixed effect model are quite different from those of the IV method. The problem of endogeneity in this paper lowers the estimation coefficients of the main explanatory variables $l d h j$ and ldlow, as a result of which the coefficient estimation becomes nonsignificant.

Preliminary analysis shows that local governments have shown a certain degree of responsiveness to the demand of mobile labor force. The coefficient of ldlow is positive and significant in education and medical care expenditures, indicating that the local government has a strong sensitivity to general labor mobility. The increase in general labor mobility is conducive to the government increasing fiscal expenditures on education and medical care and improving the structure of local government fiscal expenditures. One possible reason is that in the current "family-style migration" mode of population flow, migrant workers account for the vast majority of the general labor force. They are more sensitive to the educational needs of their children, preferring to sacrifice part of their wage income, and they want the local government to provide more educational opportunities. The same is true for medical care expenditures. In the flow of multiperson families, both the elderly and children require more medical care, which reflects the actual demand of the mobile labor force. In contrast, the government's estimate of the mobility of the newly added registered labor force is large, but it is not significant. 
Table 3. Fixed effects model (FE) and instrumental variable (IV) estimation results.

\begin{tabular}{|c|c|c|c|c|c|c|}
\hline \multirow[t]{2}{*}{ Variables } & \multicolumn{2}{|c|}{$\begin{array}{c}\text { Proportion of Education } \\
\text { Expenditures }\end{array}$} & \multicolumn{2}{|c|}{$\begin{array}{l}\text { Proportion of Medical } \\
\text { Care Expenditures }\end{array}$} & \multicolumn{2}{|c|}{$\begin{array}{l}\text { Proportion of Environmenta } \\
\text { Protection Expenditures }\end{array}$} \\
\hline & fe & iv & fe & iv & fe & iv \\
\hline \multirow[t]{2}{*}{$l d h j$} & -0.009 & 0.108 & -0.027 & 0.048 & 0.071 & $0.312^{* *}$ \\
\hline & $(-0.140)$ & (0.783) & $(-0.725)$ & $(0.476)$ & (1.399) & $(2.524)$ \\
\hline \multirow[t]{2}{*}{ ldlow } & 0.038 & $0.060 * *$ & $0.027^{* *}$ & $0.034^{* *}$ & -0.003 & 0.006 \\
\hline & (1.521) & $(2.159)$ & (2.353) & $(2.267)$ & $(-0.207)$ & (0.359) \\
\hline \multirow{2}{*}{$\ln p g d p$} & -0.021 & -0.019 & $-0.039^{* * *}$ & $-0.038^{* * *}$ & 0.009 & 0.011 \\
\hline & $(-1.123)$ & $(-1.271)$ & $(-3.676)$ & $(-4.184)$ & (0.523) & (0.848) \\
\hline \multirow[t]{2}{*}{ Indensity } & 0.002 & 0.00004 & 0.018 & 0.016 & 0.025 & 0.010 \\
\hline & $(0.083)$ & $(0.002)$ & (1.242) & (1.263) & (1.546) & $(0.784)$ \\
\hline \multirow[t]{2}{*}{$\operatorname{lnsm}$} & -0.001 & -0.002 & 0.001 & 0.001 & 0.009 & 0.009 \\
\hline & $(-0.268)$ & $(-0.341)$ & $(0.238)$ & $(0.250)$ & (1.034) & (1.177) \\
\hline \multirow[t]{2}{*}{ Inwage } & $0.017^{* *}$ & $0.017^{* * * *}$ & $0.006^{* *}$ & $0.007^{* *}$ & $-0.016^{*}$ & $-0.015^{* *}$ \\
\hline & $(2.396)$ & $(2.624)$ & $(2.058)$ & $(2.281)$ & $(-1.752)$ & $(-2.244)$ \\
\hline \multirow[t]{2}{*}{ lnbook } & -0.002 & $-0.002 *$ & -0.001 & -0.001 & -0.001 & -0.001 \\
\hline & $(-1.277)$ & $(-1.694)$ & $(-0.700)$ & $(-0.927)$ & $(-0.744)$ & $(-0.965)$ \\
\hline \multirow[t]{2}{*}{ Inperphone } & 0.001 & 0.001 & 0.00017 & 0.00038 & 0.002 & 0.003 \\
\hline & $(0.320)$ & $(0.408)$ & $(0.064)$ & $(0.157)$ & $(0.706)$ & (1.083) \\
\hline \multirow[t]{2}{*}{ pubtoall } & 0.009 & 0.008 & 0.009 * & $0.009^{* *}$ & $-0.014^{*}$ & $-0.013^{* *}$ \\
\hline & (1.142) & (1.173) & (1.922) & $(2.383)$ & $(-1.898)$ & $(-2.271)$ \\
\hline \multirow[t]{2}{*}{ all_towork } & -0.00017 & 0.00026 & 0.001 & 0.001 & 0.004 & 0.004 \\
\hline & $(-0.027)$ & $(0.046)$ & $(0.171)$ & $(0.189)$ & $(0.266)$ & $(0.362)$ \\
\hline \multirow[t]{2}{*}{$z f b i g$} & $-0.285^{* * *}$ & $-0.282^{* * *}$ & $-0.182^{* * *}$ & $-0.182^{* * *}$ & $-0.043^{* * *}$ & $-0.041^{* * *}$ \\
\hline & $(-6.873)$ & $(-10.833)$ & $(-9.023)$ & $(-10.471)$ & $(-3.270)$ & $(-3.247)$ \\
\hline \multirow[t]{2}{*}{ nonworkrate } & -0.020 & -0.020 & 0.015 & 0.016 & 0.106 * & $0.116^{* *}$ \\
\hline & $(-0.476)$ & $(-0.550)$ & $(0.432)$ & $(0.482)$ & (1.691) & $(2.162)$ \\
\hline \multirow[t]{2}{*}{ finfree } & 0.015 & 0.016 & -0.003 & -0.003 & $-0.017^{*}$ & $-0.017^{* *}$ \\
\hline & (1.100) & (1.520) & $(-0.462)$ & $(-0.596)$ & $(-1.921)$ & $(-2.071)$ \\
\hline \multirow[t]{2}{*}{$g d p 3$} & -0.123 & $-0.134^{* *}$ & 0.020 & 0.023 & 0.043 & 0.050 \\
\hline & $(-1.583)$ & $(-2.226)$ & $(0.425)$ & $(0.558)$ & $(0.815)$ & (1.033) \\
\hline \multirow[t]{2}{*}{$g d p 2$} & -0.115 & $-0.123^{* *}$ & 0.037 & 0.038 & 0.032 & 0.036 \\
\hline & $(-1.647)$ & $(-2.177)$ & $(0.856)$ & (1.009) & $(0.649)$ & $(0.852)$ \\
\hline \multirow[t]{2}{*}{$\ln p f d i$} & 0.0002 & 0.0001 & -0.0006 & -0.0007 & -0.0007 & -0.0006 \\
\hline & $(0.141)$ & $(0.111)$ & $(-1.219)$ & $(-1.323)$ & $(-0.775)$ & $(-0.783)$ \\
\hline \multirow[t]{2}{*}{ midbili } & -0.033 & -0.020 & -0.063 & -0.068 & 0.032 & 0.018 \\
\hline & $(-0.317)$ & $(-0.231)$ & $(-1.151)$ & $(-1.431)$ & $(0.459)$ & $(0.275)$ \\
\hline \multirow[t]{2}{*}{ pribili } & 0.104 & 0.105 & $-0.124^{*}$ & $-0.113^{* *}$ & 0.099 & 0.113 \\
\hline & $(0.855)$ & (1.077) & $(-1.776)$ & $(-2.028)$ & (1.022) & (1.597) \\
\hline \multirow{2}{*}{$\begin{array}{c}\text { Individual effect } \\
\text { Time effect }\end{array}$} & Yes & Yes & Yes & Yes & Yes & Yes \\
\hline & Yes & Yes & Yes & Yes & Yes & Yes \\
\hline Observations & 1468 & 1455 & 1414 & 1399 & 1109 & 1096 \\
\hline Number of id & 232 & 226 & 231 & 223 & 183 & 177 \\
\hline $\mathrm{R} 2$ & 0.384 & 0.384 & 0.539 & 0.538 & 0.111 & 0.089 \\
\hline rk Wald F value & & 34.732 & & 32.970 & & 22.189 \\
\hline $\begin{array}{c}\text { Hansen } J \text { test } P \\
\text { value }\end{array}$ & & 0.4198 & & 0.0781 & & 0.2419 \\
\hline
\end{tabular}

Note: The values in brackets are $t$ values under robust standard error estimation; $* * * * *$, and ${ }^{*}$ represent significance at the $1 \%, 5 \%$, and $10 \%$ levels, respectively; "Yes" means that we have controlled for individual and time effects; the rk Wald F value refers to the Kleibergen-Paap rk Wald F statistic, and the results are large enough to reject the null hypothesis of weak instrumental variables; the Hansen J test is a test of overidentifying restrictions, and the null hypothesis is that the instruments are valid instruments; "Number of id" indicates the number of prefecture-level cities included in the regression.

In environmental protection expenditures, the newly added registered labor force pays more attention to the local ecological environment than the general labor force, which is uncertain about its final place of residence. In terms of specific performance, the coefficient of $l d h j$ is significant, and 
the value is large, which is conducive to breaking the productive expenditure bias caused by capital competition and promoting the improvement of the regional ecological environment.

To better control the influence of endogeneity, many control variables are added to the model estimation process in Table 3. Some of the control variables are not significant, and after deleting these variables, the estimated results are basically the same (see Table A2). However, to maintain the consistency of the results and facilitate comparative analysis, these control variables will continue to be added in subsequent regressions.

\subsection{Further Test Results}

Through the regression of model (17), the following results are obtained (Table 4). First, the estimation coefficients of $l d h j$ and ldlow in Model fe_2, which controls the supply level of livelihood public goods and adds the interaction items, are consistent with the estimation results of the IV method in Table 3, indicating that the problems of endogeneity in the model analysed above have been well addressed. That is, the objective supply level of livelihood public goods will lead to errors in model estimation by affecting labor mobility.

Second, after dealing with the problems of endogeneity by IV estimation in Table 3 and controlling for specific variables in Table 4, we can confirm the existence of the mechanism of the impact of labor mobility on the local government fiscal expenditure structure. That is, in the case of regional competition, the increase in mobile labor will promote local governments to respond to the labor force's needs and then increase the proportion of livelihood public good expenditures. In the process, the different demands of the labor force for different livelihood public goods result in the difference in the fiscal expenditure structure.

Finally, the difference between the estimated results of controlling only the supply level of public goods ( $\mathrm{fe} \_1$ ) and adding the interaction item ( $\mathrm{fe} \_2$ ) at the same time is mainly reflected in the proportion of education expenditures. After adding the interaction item, the original nonsignificant coefficient of ldlow becomes significant, indicating that the increase in general labor mobility helps local governments increase the proportion of education expenditures and improve the structure of government expenditures at the average supply level of education public service.

Next, through Figure 1, we further analyse the impact of heterogeneous labor mobility on the proportion of fiscal expenditures on three types of livelihood public goods at different supply levels of livelihood public goods.

Based on the analysis of Hainmueller et al. [36], we consider whether the model with the added interaction terms satisfies the linear hypothesis, leading to possible errors. Figure $1 \mathrm{a}, \mathrm{b}$ measure the marginal impact of the two labor forces mobility, ldhj and ldlow, respectively, on the proportion of education expenditures under different education supply levels. Medical care and environmental protection can be compared with education. The sample is divided into five equal parts, and the median of each part is substituted to estimate the new model. The estimated coefficients of the five-part median are shown in Figure 1.

Figure 1a shows that under different supply levels of education, the mobility of the intentionally registered labor force has different effects on the proportion of education expenditures. Where the education supply level is low, there is a strong demand for higher education expenditures from the intentionally registered labor force, and the local government can fully respond to this demand. Therefore, with the increasing mobility of the newly added registered labor force, local governments tend to increase investment in education to improve the supply level of education. In contrast, when the local government's education supply level crosses a certain level, the newly added registered labor force is not sufficiently sensitive to the supply level of education. 
In Figure 1c,d, the newly added registered labor force and the newly added general labor force also differ in the low supply level of medical care. Because a low education supply level often also means a low medical care supply level (A test of the correlation coefficient of the supply levels of education, medical care, and environmental protection found that the three were highly positively correlated.), the registered labor force may prefer to endure lower medical care because it is more concerned about improving the education supply. The general labor force shows an obvious demand for medical care improvement, which urges local governments to increase investment in this aspect and to improve the structure of local government fiscal expenditures.

Table 4. The test of the influence of various livelihood public goods on the labor mobility mechanism.

\begin{tabular}{|c|c|c|c|c|c|c|}
\hline \multirow[t]{2}{*}{ Variables } & \multicolumn{2}{|c|}{$\begin{array}{l}\text { Proportion of Education } \\
\text { Expenditures }\end{array}$} & \multicolumn{2}{|c|}{$\begin{array}{l}\text { Proportion of Medical Care } \\
\text { Expenditures }\end{array}$} & \multicolumn{2}{|c|}{$\begin{array}{c}\text { Proportion of } \\
\text { Environmental Protection } \\
\text { Expenditures }\end{array}$} \\
\hline & fe_1 & fe_2 & fe_1 & fe $\_2$ & fe_1 & fe $\_2$ \\
\hline$l d h j$ & $\begin{array}{l}-0.0014 \\
(-0.023)\end{array}$ & $\begin{array}{l}0.0128 \\
(0.207)\end{array}$ & $\begin{array}{l}-0.0270 \\
(-0.731)\end{array}$ & $\begin{array}{l}-0.0316 \\
(-0.847)\end{array}$ & $\begin{array}{l}0.0861 * \\
(1.704)\end{array}$ & $\begin{array}{c}0.0865 * \\
(1.691)\end{array}$ \\
\hline ldlow & $\begin{array}{l}0.0385 \\
(1.531)\end{array}$ & $\begin{array}{l}0.0490 * * \\
(2.022)\end{array}$ & $\begin{array}{l}0.0265^{* *} \\
(2.344)\end{array}$ & $\begin{array}{l}0.0257^{* *} \\
(2.214)\end{array}$ & $\begin{array}{l}-0.0011 \\
(-0.089)\end{array}$ & $\begin{array}{l}-0.0008 \\
(-0.056)\end{array}$ \\
\hline edusy1 & $\begin{array}{c}0.4482^{* * * *} \\
(3.127)\end{array}$ & $\begin{array}{c}0.4580^{* * *} \\
(3.138)\end{array}$ & & & & \\
\hline c_edusy1_ldhj & & $\begin{array}{l}7.2381 \\
(1.585)\end{array}$ & & & & \\
\hline c_edusy1_ldlow & & $\begin{array}{l}2.6214 \\
(1.345)\end{array}$ & & & & \\
\hline hossy1 & & & $\begin{array}{c}0.00002 \\
(0.194)\end{array}$ & $\begin{array}{c}0.00003 \\
(0.379)\end{array}$ & & \\
\hline c_hossy1_ldhj & & & & $\begin{array}{l}0.0045 \\
(1.229)\end{array}$ & & \\
\hline c_hossy1_ldlow & & & & $\begin{array}{c}0.00002 \\
(0.013)\end{array}$ & & \\
\hline envsy1 & & & & & $\begin{array}{l}-0.0039 \\
(-1.143)\end{array}$ & $\begin{array}{l}-0.0042 \\
(-1.176)\end{array}$ \\
\hline c_envsy1_ldhj & & & & & & $\begin{array}{l}-0.0007 \\
(-0.003)\end{array}$ \\
\hline c_envsy1_ldlow & & & & & & $\begin{array}{l}-0.0335 \\
(-0.334)\end{array}$ \\
\hline $\begin{array}{c}\text { Control } \\
\text { variables }\end{array}$ & Yes & Yes & Yes & Yes & Yes & Yes \\
\hline $\begin{array}{l}\text { Individual } \\
\text { effect }\end{array}$ & Yes & Yes & Yes & Yes & Yes & Yes \\
\hline Time effect & Yes & Yes & Yes & Yes & Yes & Yes \\
\hline Observations & 1468 & 1468 & 1414 & 1414 & 1078 & 1078 \\
\hline $\begin{array}{c}\text { Number of } \\
\text { id }\end{array}$ & 232 & 232 & 231 & 231 & 183 & 183 \\
\hline $\mathrm{R} 2$ & 0.393 & 0.395 & 0.539 & 0.540 & 0.103 & 0.103 \\
\hline
\end{tabular}

Note: The values in brackets are $t$ values under robust standard error estimation; ${ }^{* * *}$, ${ }^{* *}$, and ${ }^{*}$ represent significance at the $1 \%, 5 \%$, and $10 \%$ levels, respectively; the c_prefix in the text represents the result of centralizing the interaction item; "Yes" means that we have controlled for individual effects, time effects, and control variables; due to space limitations, the coefficients of the control variables and their significance are not reported here. 


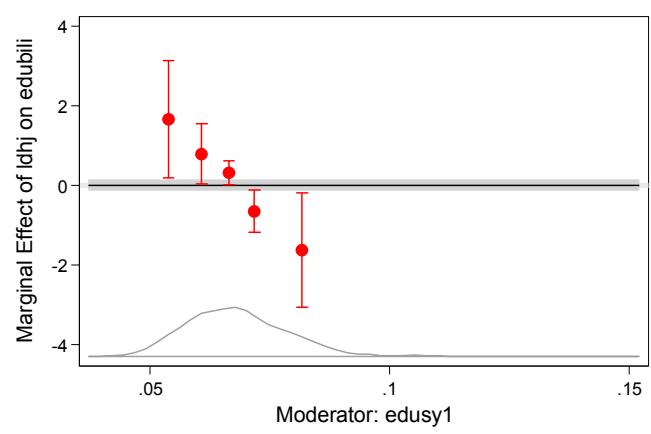

(a) Education.

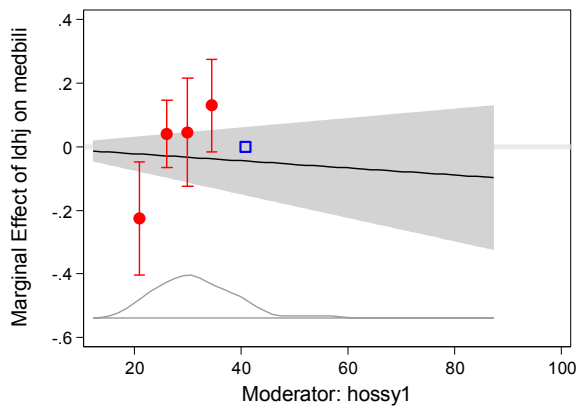

(c) Medical care.

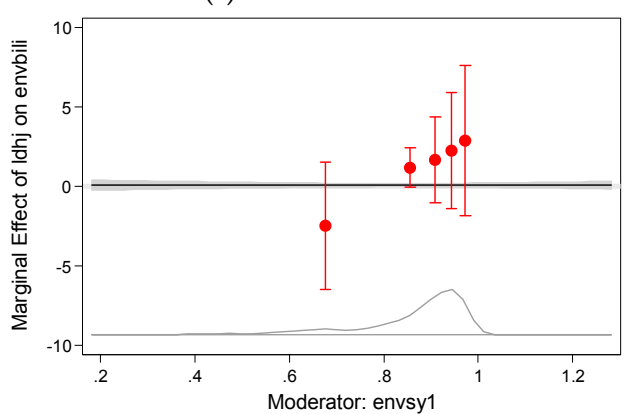

(e) Environmental protection.

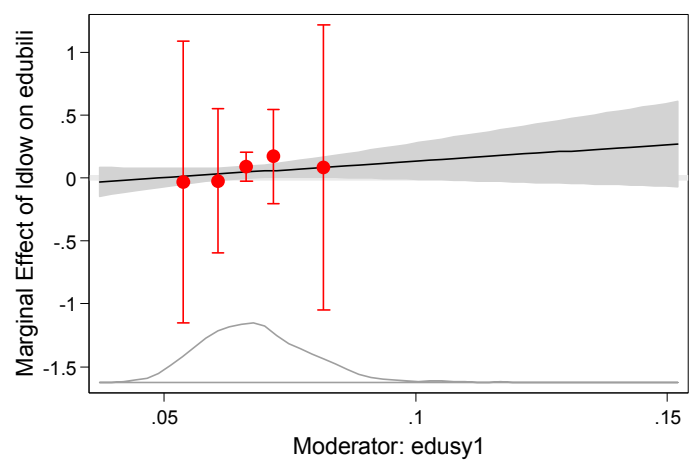

(b) Education

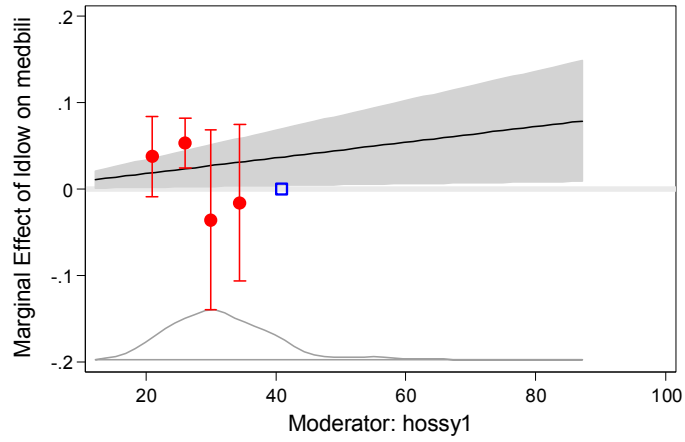

(d) Medical care.

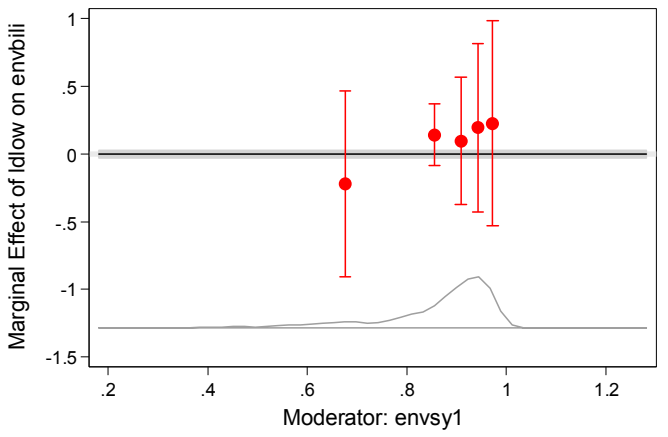

(f) Environmental protection.

Figure 1. The impact of the supply of public goods on the two labor forces flows. Note: The red dot in the graph indicates the result of the binning estimation. The vertical line above and below the red dot represents the range of its confidence interval. The black line represents the estimate under the linear assumption (LIE). The fact that the red dot is essentially on the black line indicates that the interaction terms satisfy the linear assumption.

\subsection{Test Results of the Existence of Regional Competition}

As shown in Table 5, the instrumental variables passed the weak instrumental variables test and the overidentification test. As in Table 3, the coefficients of $l d h j$ and ldlow are in the same direction and remain basically significant (Table 5 reports the estimated results of using $x z 1 x$ as the indicator to measure the degree of local government competition. The estimated results of using $x z 1$ are shown in Table A3.). The possible problem of endogeneity will lead to the low absolute value of the estimated coefficients in the general fixed effect model. In the IV estimation, the interaction terms between the new added labor mobility variables and regional competition are still significant, proving that different degrees of regional competition will lead to a change in the impact of labor mobility on the proportion of fiscal expenditures on livelihood public goods and then change the structure of local government fiscal expenditures. 
Table 5. Fe and IV estimation of the competition mechanism for public good supply projects.

\begin{tabular}{|c|c|c|c|c|c|c|}
\hline \multirow[t]{2}{*}{ Variables } & \multicolumn{2}{|c|}{$\begin{array}{c}\text { Proportion of Education } \\
\text { Expenditures }\end{array}$} & \multicolumn{2}{|c|}{$\begin{array}{l}\text { Proportion of Medical } \\
\text { Care Expenditures }\end{array}$} & \multicolumn{2}{|c|}{$\begin{array}{l}\text { Proportion of Environmental } \\
\text { Protection Expenditures }\end{array}$} \\
\hline & fe & iv & fe & iv & fe & iv \\
\hline ldhj & $\begin{array}{c}0.016 \\
(0.244)\end{array}$ & $\begin{array}{c}0.132 \\
(0.930)\end{array}$ & $\begin{array}{l}-0.048 \\
(-1.239)\end{array}$ & $\begin{array}{c}0.018 \\
(0.181)\end{array}$ & $\begin{array}{l}0.094 * \\
(1.831)\end{array}$ & $\begin{array}{c}0.357^{* * *} \\
(2.744)\end{array}$ \\
\hline ldlow & $\begin{array}{l}0.054^{* *} \\
(2.276)\end{array}$ & $\begin{array}{l}0.074^{* * *} \\
(2.750)\end{array}$ & $\begin{array}{c}0.019 \\
(1.452)\end{array}$ & $\begin{array}{c}0.020 \\
(1.465)\end{array}$ & $\begin{array}{c}0.004 \\
(0.256)\end{array}$ & $\begin{array}{c}0.006 \\
(0.394)\end{array}$ \\
\hline c_xz1x_ldhj & $\begin{array}{c}0.005 \\
(0.265)\end{array}$ & $\begin{array}{c}0.019 \\
(0.583)\end{array}$ & $\begin{array}{c}0.012 \\
(1.023)\end{array}$ & $\begin{array}{c}0.012 \\
(0.402)\end{array}$ & $\begin{array}{l}-0.010 \\
(-0.742)\end{array}$ & $\begin{array}{l}-0.051^{*} \\
(-1.910)\end{array}$ \\
\hline c_xz1x_ldlow & $\begin{array}{c}0.017 * * * \\
(2.843)\end{array}$ & $\begin{array}{l}0.016 \text { ** } \\
(2.204)\end{array}$ & $\begin{array}{l}-0.009 * \\
(-1.660)\end{array}$ & $\begin{array}{l}-0.013^{* *} \\
(-2.414)\end{array}$ & $\begin{array}{c}0.007 \\
(1.372)\end{array}$ & $\begin{array}{c}0.005 \\
(0.995)\end{array}$ \\
\hline$x z 1 x$ & $\begin{array}{l}-0.009^{* * *} \\
(-4.234)\end{array}$ & $\begin{array}{l}-0.009 * * * \\
(-4.674)\end{array}$ & $\begin{array}{c}0.001 \\
(0.569)\end{array}$ & $\begin{array}{c}0.001 \\
(0.689)\end{array}$ & $\begin{array}{l}-0.001 \\
(-0.601)\end{array}$ & $\begin{array}{l}-0.001 \\
(-0.845)\end{array}$ \\
\hline $\begin{array}{c}\text { Control } \\
\text { variables }\end{array}$ & Yes & Yes & Yes & Yes & Yes & Yes \\
\hline Individual effect & Yes & Yes & Yes & Yes & Yes & Yes \\
\hline Time effect & Yes & Yes & Yes & Yes & Yes & Yes \\
\hline Observations & 1468 & 1455 & 1414 & 1399 & 1109 & 1096 \\
\hline R2 & 0.396 & 0.395 & 0.542 & 0.541 & 0.114 & 0.086 \\
\hline $\begin{array}{l}\text { Number of id } \\
\text { rk Wald F value }\end{array}$ & 232 & $\begin{array}{c}226 \\
16.665\end{array}$ & 231 & $\begin{array}{c}223 \\
15.691\end{array}$ & 183 & $\begin{array}{c}177 \\
10.751\end{array}$ \\
\hline $\begin{array}{c}\text { Hansen } \mathrm{J} \text { test } \mathrm{P} \\
\text { value }\end{array}$ & & 0.4943 & & 0.3208 & & 0.2953 \\
\hline
\end{tabular}

Note: The values in brackets are $t$ values under robust standard error estimation; ${ }^{* * *}, * *$, and ${ }^{*}$ represent significance at the $1 \%, 5 \%$, and $10 \%$ levels, respectively; "Yes" means that we have controlled for individual effects, time effects, and control variables; due to space limitations, the coefficients of the control variables and their significance are not reported here. Specifically, for education expenditures, the interaction terms between the newly added general labor mobility and regional competition variables remain positive, indicating that the more intense the regional competition is, the stronger the positive role of general labor mobility in promoting the proportion of education expenditures. For medical care and environmental protection expenditures, an increase in labor mobility has a negative effect on the proportion of expenditures on these aspects due to the intensification of competition. Combined with the previous analysis, this result may be because education services have an excessive impact on labor mobility decisions; thus, local governments have cut medical care and environmental protection expenditures in response to the labor force's educational needs.

\section{Conclusions}

Under the framework of regional competition, this paper constructs a theoretical model and uses panel data on Chinese prefecture-level cities in 2010-2016 to empirically test the impact of heterogeneous labor mobility on the structure of local government fiscal expenditures. This paper finds that, in the current process of China's economic transformation, local governments' responsiveness to the demand of mobile labor force reaches a certain level. The supply of livelihood public goods is becoming increasingly important in the decision making on labor mobility, and labor mobility is becoming increasingly common to obtain better livelihood public goods such as education, medical care and environmental protection. Enhancing labor mobility will promote the improvement of the fiscal expenditure structure of local governments.

Specifically, with the increase in newly added general labor mobility, local governments will increase the proportion of fiscal expenditures on education and medical care, and the increase in newly added registered labor mobility in that year will be conducive to increasing the proportion of environmental protection expenditures. Therefore, increasing different labor forces mobility will promote local governments to show different preferences for livelihood public goods expenditure. A large percentage of the general labor force flows into eastern China from the western region to work. The proportion of education and medical expenditure in the eastern region is higher than that in the western region, which is more conducive to meeting people's livelihood public goods needs and promoting the intensive use of fiscal resources. At the same time, the increasing mobility of the registered labor force is conducive to increasing local government investment in environmental protection, thus making urban development greener and more environmentally friendly. 
What is the best way to increase labor mobility? We put forward the following suggestions: first, improve the quality of the labor force, increase vocational skills training, and increase innovative education. A high-quality labor force has stronger mobility and a wider scope of mobility. The second is to establish a unified household registration system between urban and rural areas, eliminate the identity differences between urban and rural residents, and eliminate discrimination between urban and rural areas. In the current context of vigorously promoting urbanization in China, this will help to alleviate the psychological concerns of rural residents entering the city. Thirdly, we should establish and implement the residence permit system to solve the problems of basic public services such as education, employment, medical care, and so on, for people who are not yet able to settle down or are unwilling to settle down in cities and towns. A more comprehensive and equitable supply of livelihood public goods such as education and medical care will reduce the opportunity cost of labor mobility.

Author Contributions: G.Y. put forward the idea, designed the study, and reviewed the paper; H.C. performed the experiments, analyzed the data, and wrote and reviewed the draft; X.M. put forward ideas and reviews and edited the paper; and all of the authors contributed to the paper.

Funding: This research was supported by the National Social Science Fund of China "Research on Regional Public Goods Spillover Effect and Spatial Optimization Policy with the Development of High-speed Rail" (Item Number 17BJL068).

Acknowledgments: We thank Yuanyuan Sun for his insightful comments. We also would like to thank the anonymous referees. All errors and omissions are our own.

Conflicts of Interest: The authors declare no conflict of interest. The sponsors had no role in the design, execution, interpretation, or writing of the study.

\section{Appendix A}

Table A1. The estimation results of the second set of instrumental variables.

\begin{tabular}{cccc}
\hline \multirow{2}{*}{ Variables } & $\begin{array}{c}\text { Proportion of Education } \\
\text { Expenditures }\end{array}$ & $\begin{array}{c}\text { Proportion of Medical } \\
\text { Care Expenditures }\end{array}$ & $\begin{array}{c}\text { Proportion of Environmental } \\
\text { Protection Expenditures }\end{array}$ \\
\cline { 2 - 4 } & iv & iv & iv \\
\hline ldhj & 0.073 & -0.015 & $0.211^{* *}$ \\
& $(0.541)$ & $(-0.162)$ & $(1.973)$ \\
Colow & $0.061^{* *}$ & $0.034^{* *}$ & 0.010 \\
Individual effect & $(2.176)$ & $(2.152)$ & $(0.569)$ \\
Time effect & Yes & Yes & Yes \\
Observations & Yes & Yes & Yes \\
R2 & Yes & Yes & 1085 \\
Number of id & 1431 & 1380 & 0.107 \\
rk Wald F value & 0.386 & 0.538 & 176 \\
Hansen J test P value & 224 & 222 & 16.850 \\
\hline
\end{tabular}

Notes: The values in brackets are $t$ values under robust standard error estimation; ${ }^{* * *}, * *$, and ${ }^{*}$ represent significance at the $1 \%, 5 \%$, and $10 \%$ levels, respectively; "Yes" means that we have controlled for individual effects, time effects, and control variables; due to space limitations, the coefficients of the control variables and their significance are not reported here.

Table A2. FE and IV estimation results without insignificant control variable.

\begin{tabular}{ccccccc}
\hline \multirow{2}{*}{ Variables } & \multicolumn{2}{c}{$\begin{array}{c}\text { Proportion of Education } \\
\text { Expenditures }\end{array}$} & \multicolumn{2}{c}{$\begin{array}{c}\text { Proportion of Medical } \\
\text { Care Expenditures }\end{array}$} & \multicolumn{2}{c}{$\begin{array}{c}\text { Proportion of Environmental } \\
\text { Protection Expenditures }\end{array}$} \\
\cline { 2 - 7 } & $\mathbf{f e}$ & $\mathbf{i v}$ & $\mathbf{f e}$ & $\mathbf{i v}$ & $\mathbf{f e}$ & iv \\
\hline \multirow{2}{*}{$l d h j$} & -0.044 & 0.011 & -0.033 & 0.002 & 0.065 & $0.297^{* * *}$ \\
& $(-0.768)$ & $(0.097)$ & $(-0.889)$ & $(0.018)$ & $(1.331)$ & $(2.775)$ \\
ldlow & 0.035 & $0.050^{*}$ & $0.030^{* *}$ & $0.044^{* *}$ & -0.003 & 0.004 \\
& $(1.455)$ & $(1.937)$ & $(2.586)$ & $(2.453)$ & $(-0.269)$ & $(0.260)$ \\
lnpgdp & -0.019 & -0.018 & $-0.032 * * *$ & $-0.031^{* * *}$ & 0.007 & 0.009 \\
& $(-1.107)$ & $(-1.258)$ & $(-3.463)$ & $(-3.882)$ & $(0.467)$ & $(0.750)$ \\
\hline
\end{tabular}


Table A2. Cont.

\begin{tabular}{ccccccc}
\hline \multirow{2}{*}{ Variables } & \multicolumn{2}{c}{$\begin{array}{c}\text { Proportion of Education } \\
\text { Expenditures }\end{array}$} & \multicolumn{2}{c}{$\begin{array}{c}\text { Proportion of Medical } \\
\text { Care Expenditures }\end{array}$} & $\begin{array}{c}\text { Proportion of Environmental } \\
\text { Protection Expenditures }\end{array}$ \\
\cline { 2 - 7 } & fe & iv & fe & iv & fe & iv \\
\hline lnwage & 0.010 & $0.010^{*}$ & 0.003 & 0.003 & -0.013 & $-0.013^{* *}$ \\
pubtoall & $(1.611)$ & $(1.646)$ & $(1.287)$ & $(1.349)$ & $(-1.607)$ & $(-1.976)$ \\
& 0.009 & 0.008 & $0.010^{* *}$ & $0.010^{* * *}$ & $-0.011^{*}$ & $-0.010^{* * *}$ \\
zfbig & $(1.344)$ & $(1.425)$ & $(2.311)$ & $(2.961)$ & $(-1.816)$ & $(-2.052)$ \\
& $-0.283^{* * *}$ & $-0.281^{* * *}$ & $-0.171^{* * *}$ & $-0.171^{* * *}$ & $-0.045^{* * *}$ & $-0.045^{* * *}$ \\
finfree & $(-8.040)$ & $(-12.164)$ & $(-11.016)$ & $(-12.666)$ & $(-3.568)$ & $(-3.741)$ \\
& 0.017 & $0.017^{*}$ & -0.002 & -0.002 & $-0.016^{*}$ & $-0.016^{* *}$ \\
gdp3 & $(1.214)$ & $(1.688)$ & $(-0.353)$ & $(-0.469)$ & $(-1.898)$ & $(-2.011)$ \\
& -0.113 & $-0.123^{* *}$ & 0.016 & 0.015 & 0.063 & 0.071 \\
gdp2 & $(-1.532)$ & $(-2.145)$ & $(0.360)$ & $(0.392)$ & $(1.288)$ & $(1.629)$ \\
& $-0.132 *$ & $-0.141^{* *}$ & 0.016 & 0.013 & 0.049 & 0.054 \\
pribili & $(-1.946)$ & $(-2.533)$ & $(0.405)$ & $(0.371)$ & $(1.086)$ & $(1.450)$ \\
& 0.092 & 0.097 & $-0.113 *$ & $-0.104 * *$ & 0.116 & $0.121^{*}$ \\
Individual effect & $(0.877)$ & $(1.127)$ & $(-1.958)$ & $(-2.210)$ & $(1.397)$ & $(1.940)$ \\
Time effect & Yes & Yes & Yes & Yes & Yes & Yes \\
Observations & Yes & Yes & Yes & Yes & Yes & Yes \\
Number of id & 1554 & 1542 & 1491 & 1478 & 1141 & 1128 \\
R2 & 238 & 233 & 237 & 231 & 187 & 181 \\
rk Wald F value & 0.37 & 0.37 & 0.54 & 0.539 & 0.101 & 0.08 \\
Hansen J test P & & 42.221 & & 40.598 & & 23.175 \\
value & & 0.3818 & & 0.1478 & & 0.3549 \\
\hline Notes The val & & & & & \\
\hline
\end{tabular}

Notes: The values in brackets are $t$ values under robust standard error estimation; ${ }^{* * *},{ }^{* *}$, and ${ }^{*}$ represent significance at the $1 \%, 5 \%$, and $10 \%$ levels, respectively; "Yes" means that we have controlled for individual and time effects.

Table A3. The estimated results of using $x z 1$ as the indicator.

\begin{tabular}{ccccccc}
\hline \multirow{2}{*}{ Variables } & \multicolumn{2}{c}{$\begin{array}{c}\text { Proportion of Education } \\
\text { Expenditures }\end{array}$} & \multicolumn{2}{c}{$\begin{array}{c}\text { Proportion of Medical } \\
\text { Care Expenditures }\end{array}$} & $\begin{array}{c}\text { Proportion of Environmental } \\
\text { Protection Expenditures }\end{array}$ \\
\cline { 2 - 6 } & fe & iv & fe & iv & fe & iv \\
\hline ldhj & 0.015 & 0.152 & -0.045 & 0.016 & $0.092^{*}$ & $0.344^{* * *}$ \\
& $(0.236)$ & $(1.063)$ & $(-1.171)$ & $(0.162)$ & $(1.787)$ & $(2.661)$ \\
ldlow & $0.057^{* *}$ & $0.076^{* *}$ & 0.017 & 0.015 & 0.005 & 0.006 \\
& $(2.198)$ & $(2.570)$ & $(1.239)$ & $(1.033)$ & $(0.300)$ & $(0.400)$ \\
c_xz1_ldhj & 0.007 & 0.019 & 0.007 & 0.005 & -0.009 & $-0.051^{* *}$ \\
& $(0.425)$ & $(0.687)$ & $(0.645)$ & $(0.179)$ & $(-0.738)$ & $(-2.027)$ \\
c_xz1_ldlow & $0.014^{* *}$ & $0.014 * *$ & -0.007 & $-0.011 * *$ & 0.006 & 0.005 \\
& $(2.542)$ & $(2.021)$ & $(-1.461)$ & $(-2.227)$ & $(1.203)$ & $(0.925)$ \\
xz1 & $-0.0074^{* * *}$ & $-0.0073^{* * *}$ & 0.0003 & 0.0004 & -0.0014 & -0.0014 \\
& $(-4.016)$ & $(-4.563)$ & $(0.251)$ & $(0.349)$ & $(-0.885)$ & $(-1.160)$ \\
Control variables & Yes & Yes & Yes & Yes & Yes & Yes \\
Individual effect & Yes & Yes & Yes & Yes & Yes & Yes \\
Time effect & Yes & Yes & Yes & Yes & Yes & Yes \\
Observations & 1468 & 1455 & 1414 & 1399 & 1109 & 1096 \\
Number of id & 232 & 226 & 231 & 223 & 183 & 177 \\
R2 & 0.396 & 0.394 & 0.541 & 0.540 & 0.115 & 0.084 \\
rk Wald F value & & 16.081 & & 15.134 & & 10.507 \\
Hansen J test P & & 0.3153 & & 0.2978 & & 0.3631 \\
value & & & & &
\end{tabular}

Notes: The values in brackets are $t$ values under robust standard error estimation; ${ }^{* * *},{ }^{* *}$, and ${ }^{*}$ represent significance at the $1 \%, 5 \%$, and $10 \%$ levels, respectively; "Yes" means that we have controlled for individual effects, time effects, and control variables; due to space limitations, the coefficients of the control variables and their significance are not reported here. 


\section{References}

1. Fu, Y.; Zhang, Y. Chinese decentralization and fiscal expenditure structure bias: The cost of competition for growth. Manag. World 2007, 3, 4-12.

2. Xu, C. The fundamental institutions of China's reforms and development. J. Econ. Lit. 2011, 49, 1076-1151. [CrossRef]

3. Li, Y.; Shen, K. Competition among jurisdictions, strategical fiscal policies, and regional characteristics of FDI's growth achievements. Econ. Res. J. 2008, 5, 58-69.

4. Zhang, J.; Gao, Y.; Fu, Y.; Zhang, H. Why does China enjoy so much better physical infrastructure? Econ. Res. J. 2007, 3, 4-19.

5. Baicker, K. The spillover effects of state spending. J. Public Econ. 2005, 89, 529-544. [CrossRef]

6. Case, A.C.; Rosen, H.S.; Hines, J.R. Budget spillovers and fiscal policy interdependence: Evidence from the states. J. Public Econ. 1993, 52, 285-307. [CrossRef]

7. Zhou, L.-A. The incentive and cooperation of government officials in the political tournaments: An interpretation of the prolonged local protectionism and duplicative investments in China. Econ. Res. J. 2004, 6, 33-40.

8. Zhou, L.-A. Governing China's local officials: An analysis of promotion tournament model. Econ. Res. J. 2007, 7, 36-50.

9. Li, H.; Zhou, L.-A. Political turnover and economic performance: The incentive role of personnel control in China. J. Public Econ. 2005, 89, 1743-1762. [CrossRef]

10. Pan, J. Measuring the Goals and Incentives of Local Chinese Officials; Harvard University: Cambridge, MA, USA, 2013.

11. Zuo, C. Promoting city leaders: The structure of political incentives in China. Chin. Q. 2015, 224, 955-984. [CrossRef]

12. Zhou, Y.; Zong, Q.; Chen, X. Yardstick competition among local municipal governments over the education expenditure under decentralized fiscal system. Econ. Res. J. 2013, 11, 128-140.

13. Besley, T.; Case, A. Incumbent behavior: Vote-seeking, tax-setting, and yardstick competition. Am. Econ. Rev. 1995, 85, 25-45.

14. Bordignon, M.; Cerniglia, F.; Revelli, F. In search of yardstick competition: A spatial analysis of Italian municipality property tax setting. J. Urban Econ. 2003, 54, 199-217. [CrossRef]

15. Elhorst, J.P.; Fréret, S. Evidence of political yardstick competition in france using a two-regime spatial durbin model with fixed effects. J. Reg. Sci. 2009, 49, 931-951. [CrossRef]

16. Wang, Y. Tenure of local officials, yardstick competition and public goods investment. Financ. Trade Econ. 2016, 10, 45-58.

17. Tsai, P.-H. Fiscal incentives and political budget cycles in China. Int. Tax Publ. Financ. 2016, 23, 1030-1073. [CrossRef]

18. Brennan, G.; Buchanan, J. The Power to Tax: Analytical Foundations of a Fiscal Constitution; Cambridge University Press: Cambridge, MA, USA, 1980.

19. Buchanan, J.M.; Tullock, G. The Calculus of Consent: Logical Foundations of Constitutional Democracy; University of Michigan Press: En Arbor, MI, USA, 1962.

20. Weingast, B.R. Second generation fiscal federalism: The implications of fiscal incentives. J. Urban Econ. 2009, 65, 279-293. [CrossRef]

21. Rapaport, C. Housing demand and community choice: An empirical analysis. J. Urban Econ. 1997, 42, 243-260. [CrossRef]

22. Nechyba, T.J.; Strauss, R.P. Community choice and local public services: A discrete choice approach. Reg. Sci. Urban Econ. 1998, 28, 51-73. [CrossRef]

23. Bayoh, I.; Irwin, E.G.; Haab, T. Determinants of residential location choice: How important are local public goods in attracting homeowners to central city locations? J. Reg. Sci. 2006, 46, 97-120. [CrossRef]

24. Dahlberg, M.; Eklöf, M.; Fredriksson, P.; Jofre-Monseny, J. Estimating preferences for local public services using migration data. Urban Stud. 2012, 49, 319-336. [CrossRef] [PubMed]

25. Keen, M.; Marchand, M. Fiscal competition and the pattern of public spending. J. Public Econ. 1997, 66, $33-53$. [CrossRef]

26. Wu, W.; Liu, N. Threshold effect of heterogeneous public expenditures on labor migration: Theoretical model and empirical analysis. Financ. Trade Econ. 2016, 3, 28-44. 
27. Borcherding, T.E.; Deacon, R.T. The demand for the services of non-federal governments. Am. Econ. Rev. 1972, 62, 891-901.

28. Barro, R.J. Government spending in a simple model of endogeneous growth. J. Polit. Econ. 1990, 98, S103-S125. [CrossRef]

29. Yin, H.; Xu, Y. On the interactions of local public infrastructure expenditure in China. Econ. Res. J. 2011, 7, 55-64.

30. Xu, Z.; Li, S. The effects of inter-regional migration on regional disparities. Chin. Econ. Q. 2008, 1, 53-76. [CrossRef]

31. Chen, S.; Lu, S. Does decentralization increase the public services expenditures: A quasi-experiment of county administrated by province in China. Chin. Econ. Q. 2014, 13, 1261-1282.

32. Zhao, L.-D.; Zhang, L. Fiscal decentralization, population cluster and the supply of public goods of the people's livelihood. Chin. Popul. Resour. Environ. 2013, 12, 136-143.

33. Hatfield, J.W.; Kosec, K. Federal competition and economic growth. J. Public Econ. 2013, 97, $144-159$. [CrossRef]

34. Stock, J.H.; Yogo, M. Testing for weak instruments in linear IV regression. NBER Tech. Work. Pap. 2005, 14, 80-108. [CrossRef]

35. Kleibergen, F.; Paap, R. Generalized reduced rank tests using the singular value decomposition. J. Econom. 2006, 133, 97-126. [CrossRef]

36. Hainmueller, J.; Mummolo, J.; Xu, Y. How Much Should We Trust Estimates from Multiplicative Interaction Models? Simple Tools to Improve Empirical Practice; Social Science Electronic Publishing: Rochester, NY, USA, 2016. 